\title{
EXPERIMENTAL RESEARCH ON INFLUENCE OF RECIPES USED ON QUALITY OF BIOMASS PELLETS
}

\author{
Iuliana Gageanu ${ }^{1}$, Gheorghe Voicu ${ }^{2}$, Valentin Vladut ${ }^{1}$, Iulian Voicea ${ }^{1}$ \\ ${ }^{1}$ National Institute of Research-Development for Machines and Installations Designed to Agriculture \\ and Food Industry, Romania; ${ }^{2}$ University Politehnica of Bucharest, Romania \\ iulia.gageanu@gmail.com
}

\begin{abstract}
The way we obtain our energy occupies an important place within the efforts to reduce pollution and climate changes. Currently, our energy still comes mainly from fossil fuels, which release greenhouse gases when they are combusted to produce energy. Due to the inevitable depletion of fossil fuels and the increased energy requirements caused by the rapid growth of the population in the last fifty years, it was necessary to find alternative sources of energy. One of the most important alternative sources of energy is biomass (wood, straws, sawdust, husk, branches, etc.). Biomass pelleting has become one of the most important ways to use biomass as a replacement for fossil fuels in the view of reducing greenhouse gas emissions and pollution in general. The paper presents experimental researches conducted on the process of compacting various types of biomass, in the form of pellets, following the influence of biomass recipes used on the final quality of pellets. The physical and thermal parameters of pellets are influenced by the use of different binding agents or additives (corn starch) in the manufacturing process. Recipe changes can lead to increased productions, reduced energy requirements per product unit and also to an improved quality (in terms of calorific value, durability, density, etc.). When used in combination with different types of biomass materials, each additive and binder leads to unique physical and thermal characteristics. Starch has proven to be a good additive in pellet production [1;2]. Thus, is important to conduct researches to identify the mixtures of biomass and additives that produce pellets with the desired physical and thermal characteristics, to maintain pellets competitive as an option for renewable energy. The results of this paper contribute to achieving efficient and eco-friendly biofuels, leading to a sustainable development and cleaner environment.
\end{abstract}

Keywords: biomass, pellets, pelleting recipes, starch.

\section{Introduction}

Biomass is the first form of energy used by human beings, since the discovery of fire. The energy included in biomass is released through different methods, which finally represent the chemical burning process $[3 ; 4]$.

In a broad sense of the word, biomass is represented by plant organic matter, animal metabolic residues (manure) as well as microorganisms. In a strict sense, agricultural biomass includes secondary products from the plants cultivated such as: straws, corn cobs, stalks (sun flower, soy, corn), leaves (beet, vine), pods (soy, beans, peas), shells (walnuts, peanuts), pits (plum, peach, apricot) and manure from animal farms [5]. Besides the agricultural biomass sources, the most important biomass sources come from forestry: primary and secondary material from exploiting forests and resinous and deciduous plantations [6].

In this context, biomass can be burned to generate heat and electricity, or it can be usedas coarse material for the production of biofuels (liquid biofuels such as biodiesel and bioethanol, or solid biofuels, such as pellets and briquettes) and some chemical compounds. Biomass is a biodegradable and renewable energy resource. Biomass production represents an expanding field due the increasing interest in alternative energy sources [7-9].

One of the most important and common used methods of transforming biomass into biofuels is represented by the pelleting process. This process consists in introducing ground biomass in specially designed equipment and forcing it to pass through the orifices of a die, thus forming cylindrical densified products, called pellets. The advantages of pellets consist in increasing material density, improving handling and storage time, improving combustion properties. Also, through the pelleting process, a large quantity of biomass that otherwise would be waster is valorised [10].

The paper presents a series of experimental researches on the processof biomass pelleting, following the influence of biomass recipes used on the pelleting process and also on a series of quality parameters of the final products obtained. The results of the paper can help researchers and operators in this field to have a clearer idea on the adequacy of certain biomass materials to be transformed into 
pellets, as well as on the suitability of these materials to be combined, varying the proportions of each material in the recipes, and also the impact of using an additive to the biomass raw material.

\section{Materials and methods}

To assess the influence of biomass recipes used on the pelleting process and on the final quality of the product, a pelleting machine with flat die (Fig. 1) was used to compress the materials.

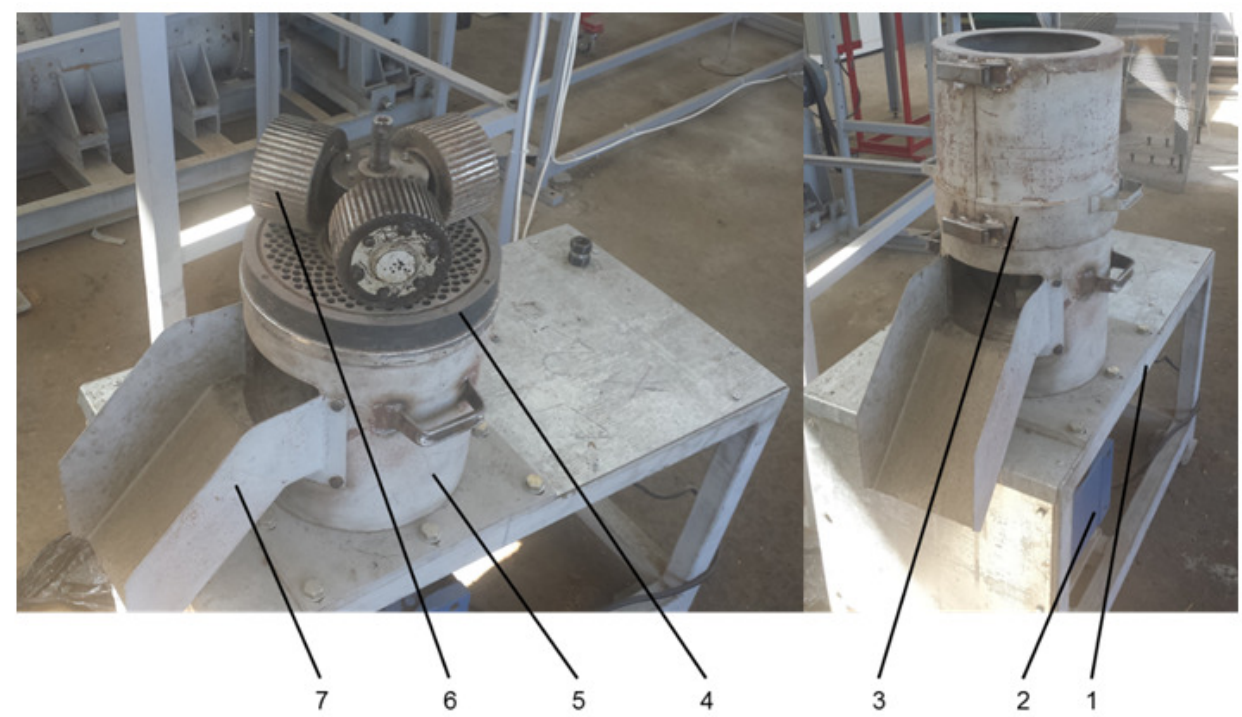

Fig. 1. Flat die pelleting equipment: 1 - frame; 2 - electric motor; 3 - material inlet; 4 - flat die with orifices; 5 - casing; 6 -pressing rollers; 7 - pellet evacuating chute

The pelleting equipment shown in Figure 1 is composed of the of the following main parts: metallic frame on which the casing of the pelleting assembly is fitted on, electric engine also fitted on the frame, a vertical material inlet, three pressing rollers placed on a rotating axle at equal distances on the diameter of the die, flat die with orifices, evacuating chute. The equipment has 2 different dies with pressing channels of $6 \mathrm{~mm}$ or $8 \mathrm{~mm}$. These channels are placed in a manner that facilitates material compression and leads to obtaining high quality pellets.

The following biomass materials (Fig. 2) were used for obtaining pellets: sawdust from forest residues, fir tree sawdust, energy willow sawdust, chopped miscanthus, chopped wheat straws, grinded alfalfa, corn cobs and corn husk. These materials were either used by themselves or in combination (varying the percentages of each material or by adding corn starch in a low percentage).

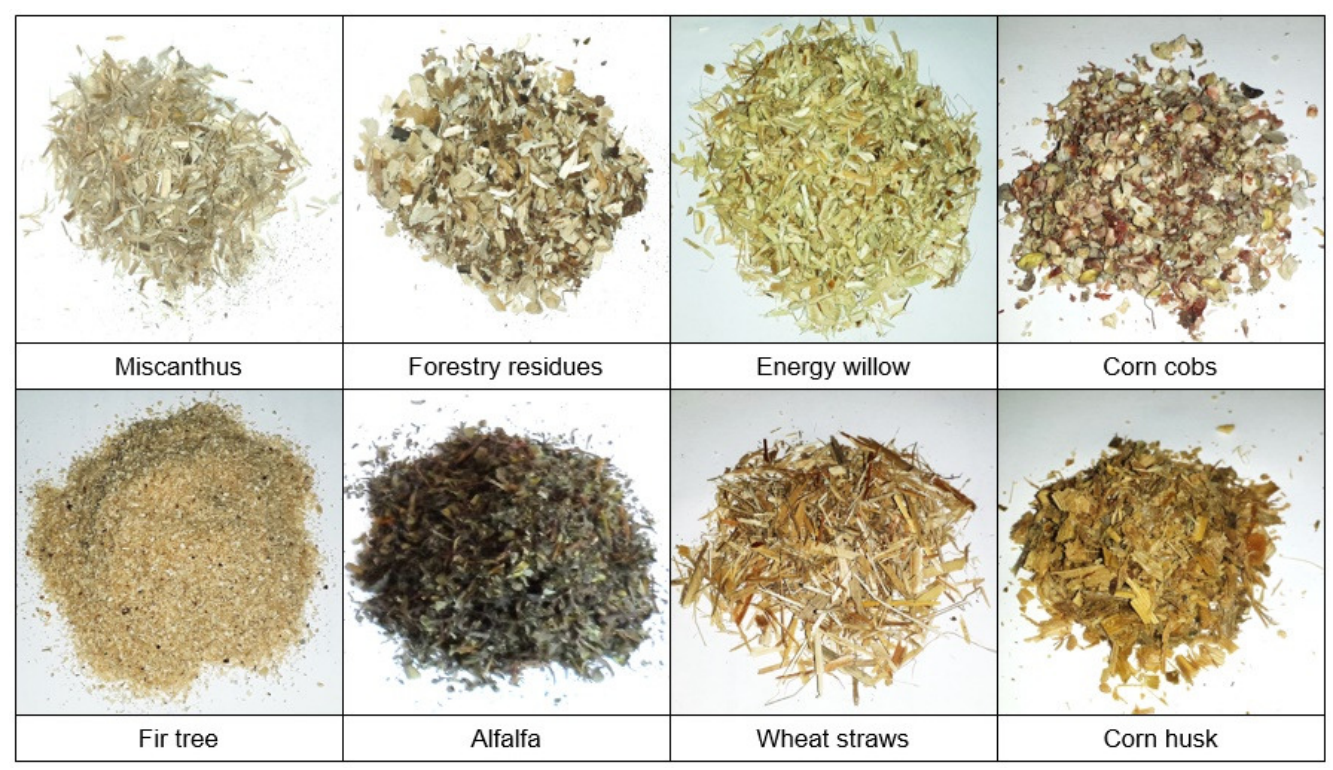

Fig. 2. Samples of ground materials used during pelleting experiments 
The biomass materials used for tests were grinded using a hammer mill (TCU - INMA Bucharest) to sizes bellow $6 \mathrm{~mm}$. For producing the pellets, the pelleting machine was equipped with the $8 \mathrm{~mm}$ die during tests. The pelleting recipes used during the experiments are shown in Table 1.

Table 1

Biomass recipes used for pelleting

\begin{tabular}{|c|c|c|c|c|}
\hline $\begin{array}{l}\text { Sample } \\
\text { number }\end{array}$ & $\begin{array}{c}\text { Sample } \\
\text { name }\end{array}$ & Materials & Percentage & $\begin{array}{c}\text { Initial material } \\
\text { moisture, \% }\end{array}$ \\
\hline 1 & $\mathrm{M}$ & Miscanthus & 100 & 8.98 \\
\hline $1 \mathrm{a}$ & $\mathrm{M}+\mathrm{a} 1$ & Miscanthus $+1 \%$ corn starch & 99 & 8.98 \\
\hline $1 \mathrm{~b}$ & $\mathrm{M}+\mathrm{a} 2$ & Miscanthus $+2 \%$ corn starch & 98 & 8.98 \\
\hline 2 & EW & Energy willow (core+bark) & 100 & 11.32 \\
\hline 3 & Fir & Fir tree & 100 & 7.24 \\
\hline $3 a$ & Fir+a1 & Fir tree $+1 \%$ corn starch & 99 & 7.24 \\
\hline $3 \mathrm{~b}$ & Fir+a2 & Fir tree $+2 \%$ corn starch & 98 & 7.24 \\
\hline 4 & FR & Forestry residues & 100 & 9.45 \\
\hline 5 & WS & Wheat straws & 100 & 9.12 \\
\hline $5 a$ & $\mathrm{WS}+\mathrm{a} 1$ & Wheat straws $+1 \%$ corn starch & 99 & 9.12 \\
\hline $5 b$ & $\mathrm{SW}+\mathrm{a} 2$ & Wheat straws $+2 \%$ corn starch & 98 & 9.12 \\
\hline \multirow{2}{*}{6} & \multirow{2}{*}{$\mathrm{EW}+\mathrm{M}$} & Energy willow (core+bark) & 50 & 11.32 \\
\hline & & Miscanthus & 50 & 8.98 \\
\hline \multirow{2}{*}{7} & \multirow{2}{*}{$\mathrm{FR}+\mathrm{M}$} & Forestry residues & 50 & 9.45 \\
\hline & & Miscanthus & 50 & 8.98 \\
\hline \multirow{2}{*}{8} & \multirow{2}{*}{$\mathrm{WS}+\mathrm{FR}$} & Wheat straws & 40 & 9.12 \\
\hline & & Forestry residues & 60 & 9.45 \\
\hline \multirow{3}{*}{9} & \multirow{3}{*}{$\mathrm{Fir}+\mathrm{CC}+\mathrm{FR}$} & Fir tree & 30 & 7.24 \\
\hline & & Corn cobs & 30 & 10.33 \\
\hline & & Forestry residues & 40 & 9.45 \\
\hline \multirow{2}{*}{10} & \multirow{2}{*}{$\mathrm{A}+\mathrm{CH}$} & Alfalfa & 50 & 14.06 \\
\hline & & Corn husk & 50 & 15.17 \\
\hline \multirow{2}{*}{11} & \multirow{2}{*}{$\mathrm{WS}+\mathrm{CC}$} & Wheat straws & 50 & 9.12 \\
\hline & & Corn cobs & 50 & 10.33 \\
\hline \multirow{4}{*}{12} & \multirow{4}{*}{$\mathrm{WS}+\mathrm{A}+\mathrm{CH}+\mathrm{CC}$} & Wheat straw & 25 & 9.12 \\
\hline & & Alfalfa & 25 & 14.06 \\
\hline & & Corn husk & 25 & 15.17 \\
\hline & & Corn cobs & 25 & 10.33 \\
\hline
\end{tabular}

During compaction, the following parameters were followed: compression time and energy consumed.The energy consumed was measured using a digital wattmeter (FLIR CM83 600A). After compaction, the following quality parameters were determined for the final products: moisture, lower calorific value, ash content, bulk density. Moisture was determined on a wet basis, using the method described in the ISO 18134-1:2015 standard [11].The quality parameters of the pellets achieved were determined using the following laboratory equipment (Table 2):

Table 2

Equipment used for tests

\begin{tabular}{|l|c|c|}
\hline \multicolumn{1}{|c|}{ Name/type } & Measuring range / Precision & Series \\
\hline $\begin{array}{l}\text { High precision weighing apparatus /AW } \\
\text { 220, with self-calibration }\end{array}$ & $0 \div 200$ g per $0.1 \mathrm{mg}$ & $\mathrm{D} 440100161$ \\
\hline $\begin{array}{l}\text { Oven with temperature control } \\
\text { /MEMMERT-UFE 500 }\end{array}$ & $0 \div 260^{\circ} \mathrm{C}$ per $1^{\circ} \mathrm{C}$ & $\mathrm{G} 507.1422$ \\
\hline Calorimeter /CAL 2k; & $0.001{\mathrm{MJ} \cdot \mathrm{kg}^{-1}}^{-1}$ & $04-15 / 11-06 / 063$ \\
\hline
\end{tabular}




\section{Results and discussion}

The compaction process was conducted using the die with $6 \mathrm{~mm}$ orifices. Samples of the pellets resulted from the experiments of compressing the biomass materials using the flat die pelleting equipment are shown in Figure 3.

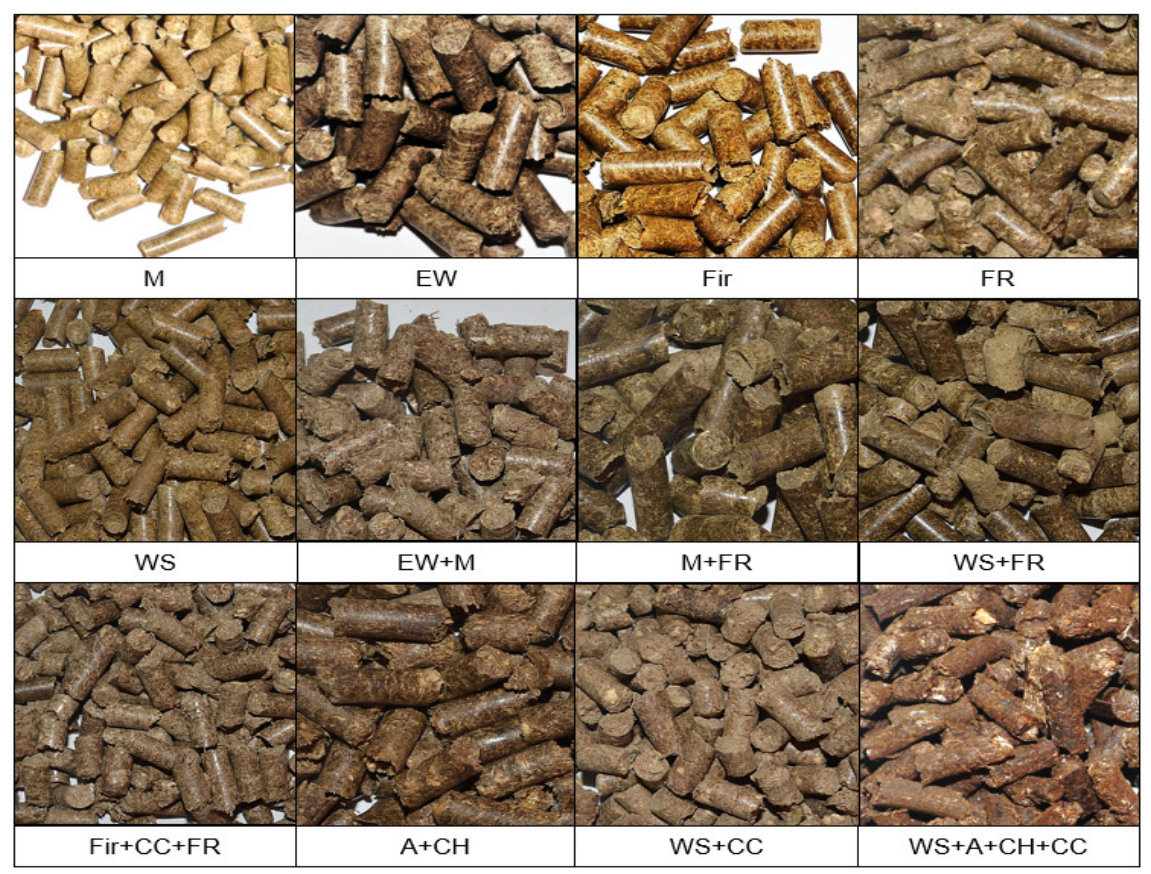

Fig. 3. Pellets resulted after conducting the tests

In Table 3 the measured parameters from the pelleting process are shown. The pelleting time was calculated for 15 kilograms of biomass raw material used, starting from the moment the equipment enters the normal operating conditions. The energetic consumption was calculated for one kilogram of product obtained.

Table 3

Pelleting process parameters during compression

\begin{tabular}{|c|c|c|c|c|c|}
\hline $\begin{array}{c}\text { Sample } \\
\text { number }\end{array}$ & $\begin{array}{c}\text { Pelleting } \\
\text { time }(\mathbf{s})\end{array}$ & $\begin{array}{c}\text { Energy } \\
\text { consumed }\left(\mathbf{k W h} \cdot \mathbf{k g}^{-\mathbf{1}}\right)\end{array}$ & $\begin{array}{c}\text { Sample } \\
\text { number }\end{array}$ & $\begin{array}{c}\text { Pelleting } \\
\text { time (s) }\end{array}$ & $\begin{array}{c}\text { Energy } \\
\text { consumed }\left(\mathbf{k W h}_{\mathbf{k g}} \mathbf{- 1}^{\mathbf{1}}\right)\end{array}$ \\
\hline 1 & 444 & 0.157 & $5 \mathrm{a}$ & 454 & 0.157 \\
\hline $1 \mathrm{a}$ & 446 & 0.157 & $5 \mathrm{~b}$ & 455 & 0.158 \\
\hline $1 \mathrm{~b}$ & 448 & 0.158 & 6 & 448 & 0.158 \\
\hline 2 & 448 & 0.157 & 7 & 446 & 0.157 \\
\hline 3 & 438 & 0.157 & 8 & 449 & 0.157 \\
\hline $3 \mathrm{a}$ & 449 & 0.158 & 9 & 451 & 0.159 \\
\hline $3 \mathrm{~b}$ & $*$ & $*$ & 10 & 451 & 0.158 \\
\hline 4 & 441 & 0.157 & 11 & 446 & 0.157 \\
\hline 5 & 452 & 0.158 & 12 & 459 & 0.160 \\
\hline
\end{tabular}

*for this type of combination, the material did not form pellets

The quality parameters measured for the pellets obtained are shown in Table 4.

Based on the experimental data in Table 4 and the initial data from Table 1, in Fig. 4 a comparison is presented between the initial moisture of the raw materials and the moisture of the pellets after densification. The data taken into consideration in this chart are only the data for materials pelletized by themselves or by adding corn starch to the raw material as we wanted to highlight the influence of this additive. In Fig. 5 a comparison is shown between samples in terms of pelleting time (for $15 \mathrm{~kg}$ of material) and energy consumption for $1 \mathrm{~kg}$ of pellets obtained. 
Result from the analysis conducted on the pellets obtained from tests

\begin{tabular}{|c|c|c|c|c|c|}
\hline $\begin{array}{l}\text { Sample } \\
\text { number }\end{array}$ & Sample type & $\begin{array}{c}\text { Moisture } \\
M, \%\end{array}$ & $\begin{array}{c}\text { Lower } \\
\text { calorific value, } \\
\boldsymbol{q}_{i}, \mathbf{M J} \cdot \mathbf{k g}^{-1}\end{array}$ & $\begin{array}{c}\text { Ash } \\
\text { content, } \\
\%\end{array}$ & $\begin{array}{c}\text { Bulk } \\
\text { density } \\
\mathbf{k g} \cdot \mathbf{m}^{-3}\end{array}$ \\
\hline 1 & Miscanthus & 6.22 & 18146 & 3.03 & 373.2 \\
\hline 1a & Miscanthus+1\% corn starch & 5.29 & 18893 & 2.9 & 396.9. \\
\hline 1b & Miscanthus+2 \% corn starch & 5.17 & 18901 & 2.9 & 397.2 \\
\hline 2 & Energy willow (core+husk) & 8.74 & 17807 & 5.23 & 489.7 \\
\hline 3 & Fir tree & 5.38 & 17325 & 5.81 & 502.6 \\
\hline 3a & Fir tree+1\% corn starch & 4.30 & 17560 & 5.12 & 524.8 \\
\hline $\mathbf{3 b}$ & Fir tree $+2 \%$ corn starch & $*$ & $*$ & $*$ & $*$ \\
\hline 4 & Forestry residues & 8.22 & 18151 & 4.23 & 508.3 \\
\hline 5 & Wheat straws & 8.64 & 15636 & 6.03 & 382.3 \\
\hline 5a & $\begin{array}{l}\text { Wheat straws }+1 \% \text { corn } \\
\text { starch }\end{array}$ & 6.58 & 15875 & 5.23 & 395.0 \\
\hline $\mathbf{5 b}$ & $\begin{array}{l}\text { Wheat straws }+2 \% \text { corn } \\
\text { starch }\end{array}$ & 5.44 & 15912 & 5.21 & 397.1 \\
\hline 6 & Energy willow + miscanthus & 6.14 & 17526 & 3.73 & 426.9 \\
\hline 7 & Forestry residues + miscanthus & 7.68 & 17871 & 4.14 & 461.6 \\
\hline 8 & Wheat straws + forestry residues & 8.12 & 16871 & 5.11 & 456.6 \\
\hline 9 & Fir+corn cobs+forestry residues & 7.65 & 16685 & 4.82 & 478.8 \\
\hline 10 & Alfalfa + Corn Husk & 13.67 & 16020 & 3.97 & 434.9 \\
\hline 11 & Wheat Straws + Corn Cobs & 8.37 & 16.238 & 3.88 & 386.4 \\
\hline 12 & $\begin{array}{l}\text { Wheat straws + Alfalfa + Corn } \\
\text { Husk + Corn Cobs }\end{array}$ & 11.46 & 16.358 & 4.03 & 378.9 \\
\hline
\end{tabular}

* for this type of combination, the material did not form pellets

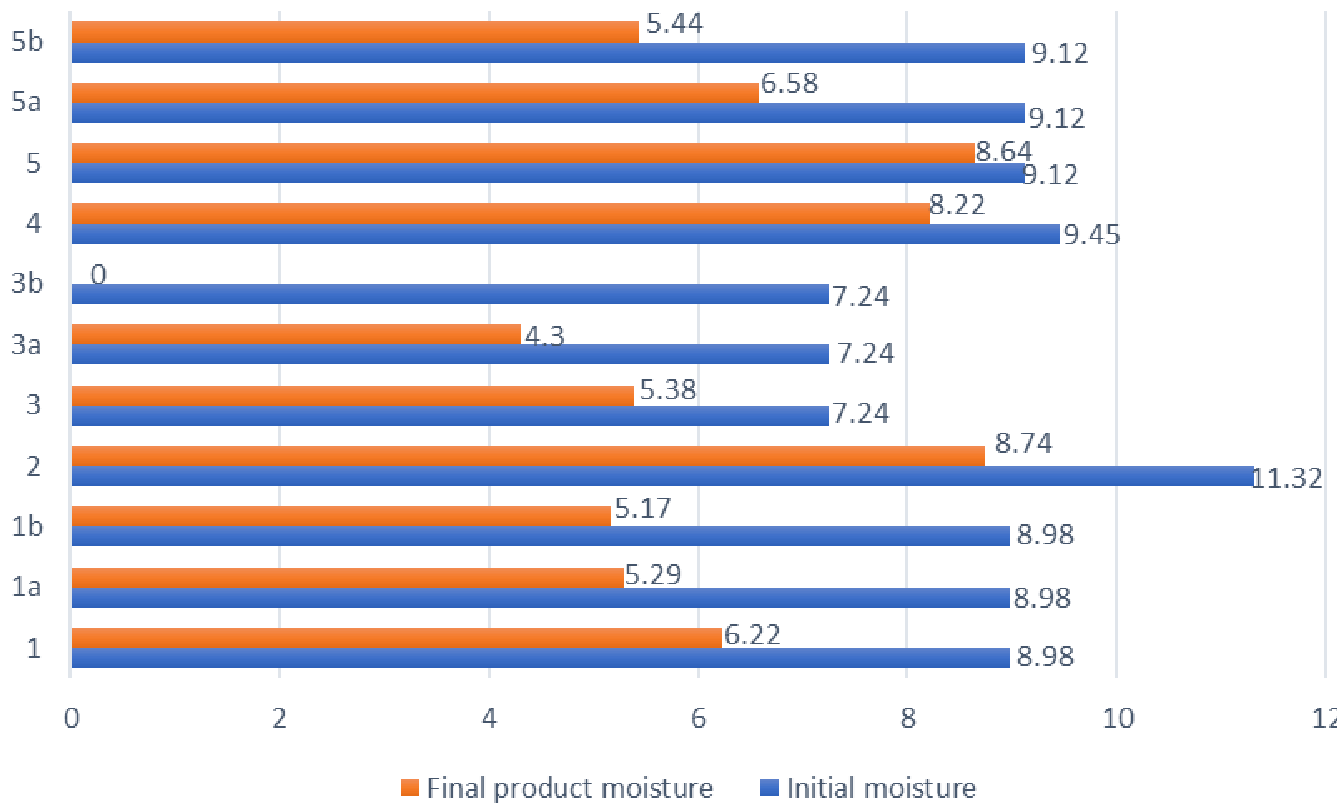

Fig. 4. Moisture comparison between the raw material and pellets (moisture in \%)

The pellets obtained after combining different types of materials and those obtained by adding corn starch showed good results, both during the production process as well as in terms of the quality parameters. Except for sample $3 \mathrm{~b}$ where the fir tree material combined with $2 \%$ corn starch lead to blockages in the pelleting machine, all samples yielded well-formed biomass pellets (as shown in Fig. 3) 
a)

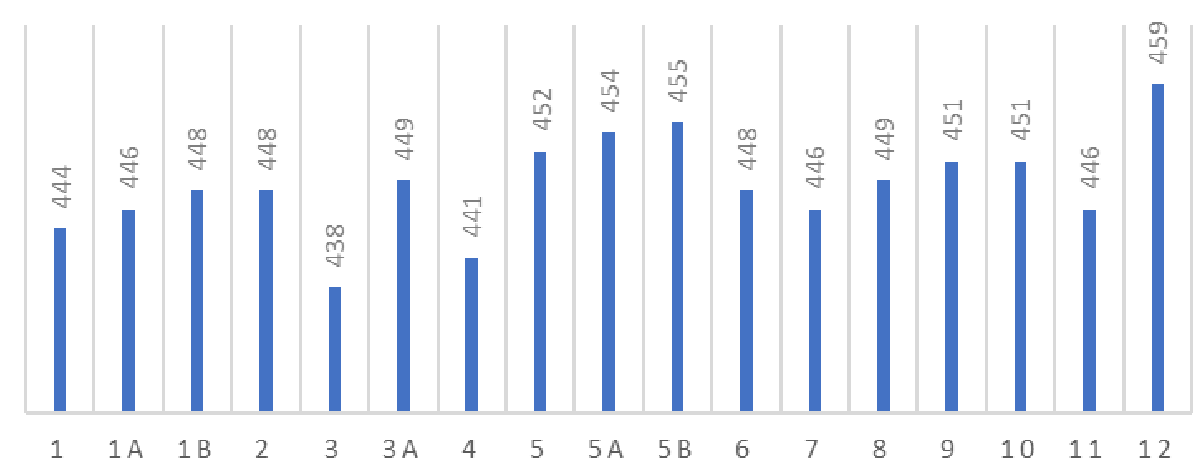

b)

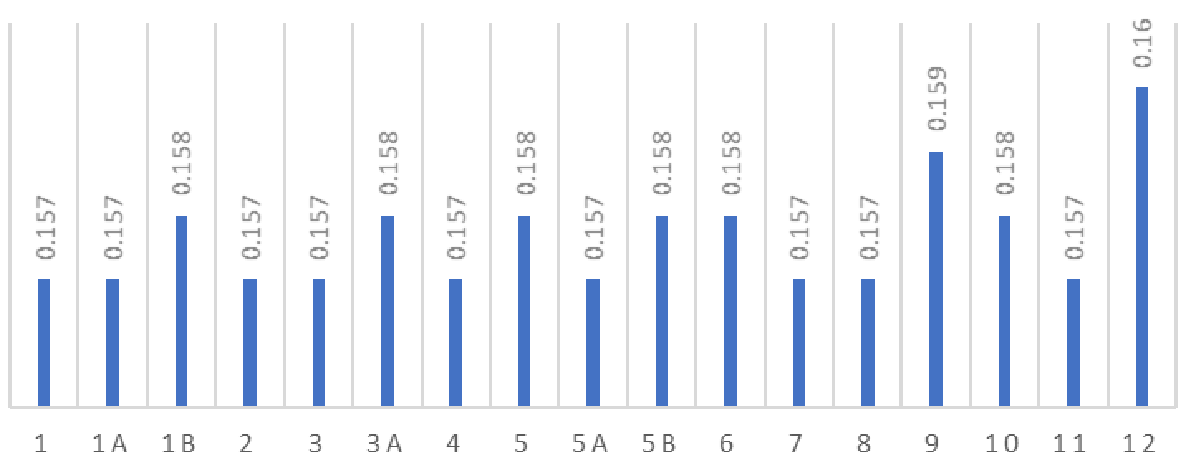

Fig. 5. Comparison between samples: a - pelleting time, $\mathrm{s} ; \mathrm{b}$ - energy consumed, $\mathrm{kWh} \cdot \mathrm{kg}^{-1}$

\section{Conclusions}

Based on the experimental data the following conclusions can be given:

1. By adding $1 \%$ corn starch to the biomass materials, the lower calorific value of the pellets produced was increased; the moisture of the pellets decreased compared to the samples without starch, leading to better storage and combustion; the pelleting time and the energetic consumption shows minor increases, especially for sample 3 a where there was a more visible impact.

2. The addition of $1 \%$ corn starch also has a positive impact on the bulk density of the pellets produced, leading to important increases.

3. By increasing the quantity of corn starch to $2 \%$, it was noticed that the positive impact on lower caloric value decreased compared to samples with $1 \%$ starch, the effect on the pelleting time and on the energetic consumption was negative. For sample $3 \mathrm{~b}$, this quantity of starch leads to the impossibility to form pellets due to the high absorption of moisture. Therefore, it results that it was not efficient to use starch in this percentage for these types of materials.

4. The combinations between various types of materials that were tested showed that it is better to use materials such as corn cobs, corn husk or wheat straws in combination with other materials to obtain pellets with better quality.

5. By using materials such as corn cobs, corn husk, wheat straws of alfalfa (that are not suitable for animal consumption) in combination with woody biomass (fir tree, willow, forestry residues) is ensured that secondary products from agriculture, which otherwise would we wasted, are valorised and transformed into energy.

6. The combination in sample $12(\mathrm{WS}+\mathrm{A}+\mathrm{H}+\mathrm{CC}$ ) leads to the highest pelleting time (459 s per $15 \mathrm{~kg})$ and the highest energetic consumption $\left(0.160 \mathrm{kWh} \cdot \mathrm{kg}^{-1}\right)$.

7. The combinations between woody biomass and agricultural biomass (with lower lignin content) showed good results in terms of lower calorific value, ash content, bulk density.

8. Future researches will be focused on assessing the durability of these pellets during storage in different storage conditions (different packaging materials, temperatures, storage times, air moisture, etc.). 


\section{Acknowledgement}

This work was funded by the Executive Agency for Higher Education, Research, Development and Innovation Funding, within the project entitled "Optimizing the composition of biomass mixtures for obtaining high quality pellets", ctr. 24 BG / 2016 (code PN-III-P2-2.1-BG-2016-0266) and project "PN 162404 03: Innovative technology for obtaining biogas through advanced methanogenesis" ctr.8N/09.03.2016/ Ad. no.1/2017.

\section{References}

1. Jezerska L., Zajonca O., Rozbroja J., Vyletěleka J., Zegzulka J., - Research on Effect of Spruce Sawdust with Added Starch on Flowability and Pelletization of the Material, IERI Procedia 8, pp. $154-163,2014$.

2. Stahl M., Berghel J., Frodeson S., Granstrom K., Renstrom R., - Effects on Pellet properties and energy use when starch is added in the wood-fuel pelletizing process, Energy Fuels Journal, vol. 26, no. 3, pp. 1937-1945, 2012.

3. Voicea, V. Vladut, M. Matache, A. Danciu, Gh. Voicu - Influence of the agricultural and forestrybiomass physical characteristics on the compaction/pelleting, Proceedings of the $42^{\text {nd }}$ InternationalSymposium on Agricultural Engineering, ISSN 1848-4425, 2014, Opatija - Croatia.

4. Tumuluru J.S., WrightC. T., KennyK. L., Hess J. R. - A review on biomass densification, Idaho National Laboratory, August 2010.

5. Ion V.I., Ion D.I. (2006) - Energy from Biomass, Theoretical considerations. Energy, no. 7(38), pg. 14-30.

6. Danciu A. et al. (2010). Technology for solid agricultural and forestry biomass capitalization for obtaining clean energy and reducing greenhouse effect gas emissions. Research Report, contract 21-008, INMA Bucharest.

7. Berkesy L., Begea M., Berkesy C., Crăciun M., Suciu L. Qualitative aspects regarding biomass destined for heating,Ecoterra, no. 30, 2012, pp. 64.

8. Voicea I., Vladut V., Cardei P., Matache M., Gageanu I., VoicuGh., Popescu C., Paraschiv G.,Kabas O. - Compacting process and mathematical analysis of miscanthus briquettes expansion,Proceedings of the 43rd International Symposium on Agricultural Engineering, ISSN 1848-4425,2015, Opatija - Croatia.

9. Stelte W., Sanadi A.R., Shang L., Holm J.K., Ahrenfeldt J., Henriksen U.B. Recent developments in biomass pelletization - A review. BioResources 7(3), 2012, pp. 4451-4490.

10. Găgeanu I., VoicuGh., Bunduchi G, Brăcăcescu C. "Experimental Research on the Process of Pelleting Salix Viminalis Depending on Humidity and Granulation" - Proceedings of 15th International Scientific Conference Engineering for Rural Development - Jelgava, 2016, pp. 624-628;

11. ISO 18134-1:2015, Solid biofuels - Determination of moisture content - Oven dry method - Part 1: Total moisture - Reference method. 